\title{
Design and In Silico Study of the Novel Small Molecular MDM2 Inhibitors
}

\author{
Chiragkumar J. Gohil ${ }^{1, *}$ (D), Malleshappa N. Noolvi ${ }^{2}$ (D) \\ 1 Ph.D. Scholar, Discipline of Pharmacy, Gujarat Technological University, Ahmedabad 382424, Gujarat, India \\ 2 Department of Pharmaceutical Chemistry, Shree Dhanvantary Pharmacy College, Kim(E), Dist.: Surat 394 110, Gujarat, \\ India \\ * Correspondence: gohil2711@gmail.com;
}

Scopus Author ID 6504104488

Received: 30.06.2020; Revised: 15.07.2020; Accepted: 16.07.2020; Published: 18.07.2020

\begin{abstract}
Protein-protein Interaction (PPIs) plays a central role in many diseased conditions. Therefore to target and to modulate PPIs is an efficient approach for the disease treatment. Cancer is also arising because of Protein-protein interaction. In cancer, the tumor suppressor p53 protein got inhibited by the MDM2 protein. 553 protein regulates the cell cycle and apoptosis. Interaction between the p53-MDM2 proteins is responsible for the inhibition of the p53 function. By this interaction, MDM2 degrades and inhibits the p53 protein. Hence, to target and inhibit the p53-MDM2 interaction for the treatment of cancer is the rational approach. By targeting this interaction with the drugs, we can selectively kill the cancer cells over the normal cells. Recently, p53-MDM2 interaction inhibitor drugs have been reported by many researchers and pharmaceutical companies. And several drugs entered into the clinical trials. In this study, a novel 1,2,4-triazole based molecules were designed as MDM2 inhibitors and performed their in-silico study. We designed the novel compound 01 and Lead 1a. In this work, In silico study of the Lead 1a and reference compounds (Nutlin 3a, RG7112) was carried out. The molecular docking study of the Novel 1,2,4-triazole based lead 1a and reference compounds was carried out. The docking score of the Lead 1a found to be better than Nutlin 3a and close to RG7112. The various possible conformations and binding affinity values were also determined by the docking study. These results indicate the Lead 1a as a potential MDM2 inhibitor and anti-cancer agent.
\end{abstract}

Keywords: p53-MDM2 interaction; MDM2 inhibitors; Drug design; 1,2,4-triazole; In silico study; Molecular docking.

(C) 2020 by the authors. This article is an open-access article distributed under the terms and conditions of the Creative Commons Attribution (CC BY) license (https://creativecommons.org/licenses/by/4.0/).

\section{Introduction}

Protein-Protein Interaction (PPIs) is much concerned with the biological system. In the majority of the disease, there are deregulated PPIs. So to identify these kinds of the PPIs in the body/disease and to target it to modulate it (inhibition or activation) by a drug is a rational approach in drug design and discovery [1]. Mostly the compounds/drugs which target the PPIs are kind of PPIs inhibitors in the majority of cases. To Target and inhibit the PPIs, the compound/drug need to be mimic the protein interaction at the protein-protein interface [2].

One of the most Important PPI in cancer is p53-MDM2 interaction. In most of the cancers, the apoptotic function of the 53 protein has been deranged or inhibited by MDM2 protein via this interaction [3]. Therefore to inhibit this interaction by drugs is the most efficient and selective treatment of cancer. 
There are numbers of p53-MDM2 interaction inhibitors that have been reported by various researchers and pharma companies [4]. For the successful development of the potent MDM2 inhibitors, the first and most important step in drug design. Nowadays, CADD and insilico studies speed up the process of drug design and discovery.

Computer-Aided Drug Design (CADD) or computational methods are an approach of rational drug design [5]. The base of all CADD methods is chemo-informatics, the application of data storage, handling, and retrieval methods to chemical structures, their properties, and biological activity $[6,7]$. The first design or reported compound during the chemical database search is called a hit compound. Then its potency and safety have been optimized to yield the lead molecule or compound [8].

Chemo-informatics can be derived from CADD techniques. Chemo-informatics covers the calculation of the molecular descriptors (QSAR parameters). Molecular descriptors described the chemical/physical property based on the structure of the molecule [9]. These molecular descriptors can be used for the filtering of the compounds from the compound libraries.

In-silico study mainly applied for drug design and discovery [10]. It uses computer simulations for the process of drug discovery. One of the best techniques of the in-silico study is the docking study [11]. Through molecular docking, we can predict the binding of the ligand with the receptor (protein structure) in 3D mode. We can score that binding with different orientations of the ligand. By scoring function, we can predict the affinity/free energy of binding [12].

We reported the 1,2,4-triazole based potential lead (1a) for the p53-MDM2 interaction inhibition (figure 1). Here we have discussed the design process and the in-silico study of the reported compounds.

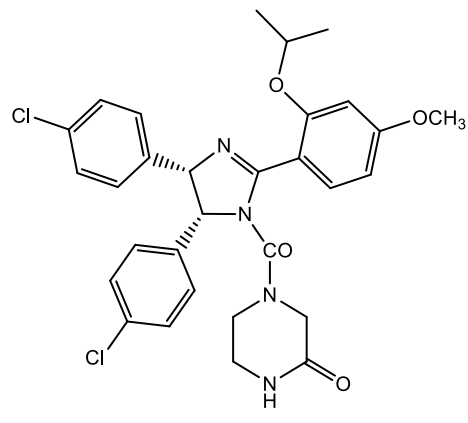

Nutlin 3a

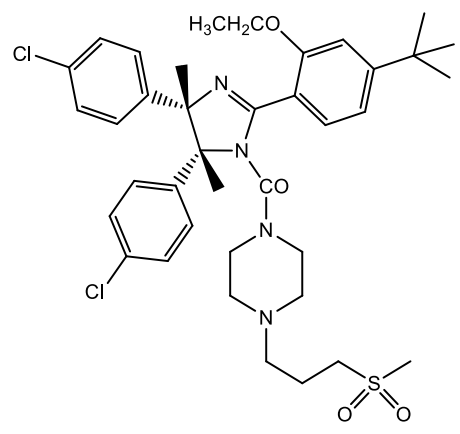

RG7112

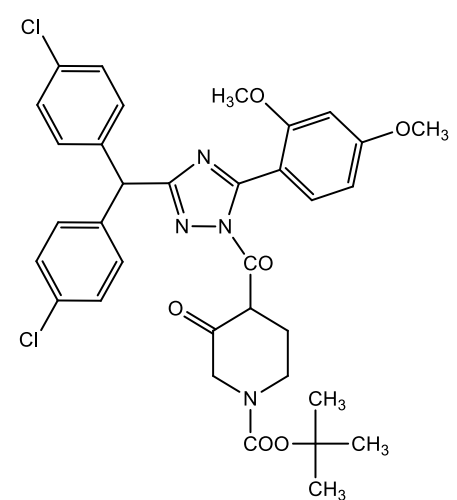

$1 \mathbf{a}$

Figure 1. Structures of Nutlin 3a, RG7112, and Lead 1a.

\section{Materials and Methods}

\subsection{Design}

We used the classical medicinal chemistry approaches for the design of compound 01 (figure 2). In the classical medicinal chemistry approach, the drug design can be based on the observed structure-activity relationships (SAR) or based on structural information [13, 14]. From the SAR and structural information of the existing drugs, we design the necessary fragments of Compound 01. Then isosteric replacement of the central scaffold in reference compounds with the 1,2,4-triazole leads to the compound 01. Nutlins and RG7112 are our 
reference compounds (figure 1), which consist of substituted imidazoline moieties. This moiety was iso-sterically replaced by 1,2,4-triazole to yield the novel molecule compound 01 .

And lead 1a was designed and developed from compound 01 by using the Sanjeevini Drug Designing Software Suite. And molecular descriptors (QSAR parameters) of the compound 01 and lead 1a had been derived by using the Lipinski filter of the Sanjeevini Drug Designing Software Suite (table 1,2).

The compound 01 and Lead 1a were designed for the part of project work for the Development of Novel small molecular MDM2 inhibitors as anti-cancer agents.

\subsection{In-silico study.}

\subsubsection{Preparation of target for the docking.}

(a) Removing Hetatoms (water and ligands from receptor):

As the co-crystal structure of the MDM2 protein complex with ligand (pdb id: 3jzk) were obtained from the RCSB protein data bank. The downloaded protein structure contains the water molecules and some ligand molecules. So, before docking our ligand/molecule, it is required to remove the already present ligands and other hetatoms from the receptor [15]. The Hetatoms were removed from the protein receptor/target by using the Discovery Studio Visualizer v 19. 1. 0. 18287 (figure 3).

(b) Finding the active site residues:

As p53-MDM2 interaction has been widely discussed by the various researchers [16, 17]. Hence, active site residues of the MDM2 protein were determined by the literature search. Active site residues of the MDM2 protein are 14 amino acid residues. Which are, Leu54, Leu57, Ile61, Met62, Tyr67, Gln72, Val75, Phe86, Phe91, Val93, His96, Ile99, Tyr100, and Ile101 [18].

\subsubsection{Molecular Docking.}

The structures used in the docking study was generated by ChemDraw Ultra (12.0.2.1076) as Sdf file. The 3D structures of MDM2 protein complex with co-crystallized ligand (pdb id: 3jzk) were obtained from the RCSB protein data bank.

Docking of each compound was done by Autodock vina of PyRx software (0.8), using the Nutlin 3a and RG7112 as a reference and lead 1a as a test. We successfully docked the design lead molecule (1a) and reference ligands (Nutlin 3a, RG7112). It provided and ranked all the possible conformations/orientation of the single compound and gave the docking scores. Also, provide the binding affinity of each compound with the target [19, 20].

\subsubsection{Receptor-ligand interaction.}

Interaction of the docked ligand (lead 1a) with the MDM2 protein was done by using the Discovery Studio Visualizer (v 19. 1. 0. 18287) and PyMOL Molecular Graphics System (V 2. 3. 3). The binding of lead 1a in the ligand-binding pocket of MDM2 protein was determined by the PyMOL Molecular Graphics System (figure 4).

Ligand binding affinity was investigated by using the PyRx software (table 5). H-bond interactions and hydrophobic interactions of the docked ligands were scrutinized by using Discovery Studio Visualizer (DS Visualizer) to quantify its role in binding affinity and drug efficacy [21]. 


\section{Results and Discussion}

\subsection{Design of compound 01 and lead la.}

For the development of the novel non-peptidic MDM2 inhibitors, compound 01 and lead 1a was designed. From the literature, it is clear that two halo-phenyl rings and one alkyl ether containing phenyl ring are necessary for the three pockets binding into the MDM2 protein [22]. Furthermore, all reported non-peptidic MDM2 inhibitors consist of the central scaffold. The central scaffold provides the backbone to the compound [23, 24]. A central scaffold may be the heterocyclic ring, annulated ring, and acyclic linear moieties (in some compounds).

Hence, we have put all the moieties required for the three-pocket binding, and then all these moieties are joined with the central scaffold (triazole) [25]. Here we choose the 1,2,4triazole ring as a central scaffold/backbone because it is an isostere of the imidazoline ring (present in the Nutlins and RG7112). So we have first designed the compound 01 as MDM2 inhibitor.

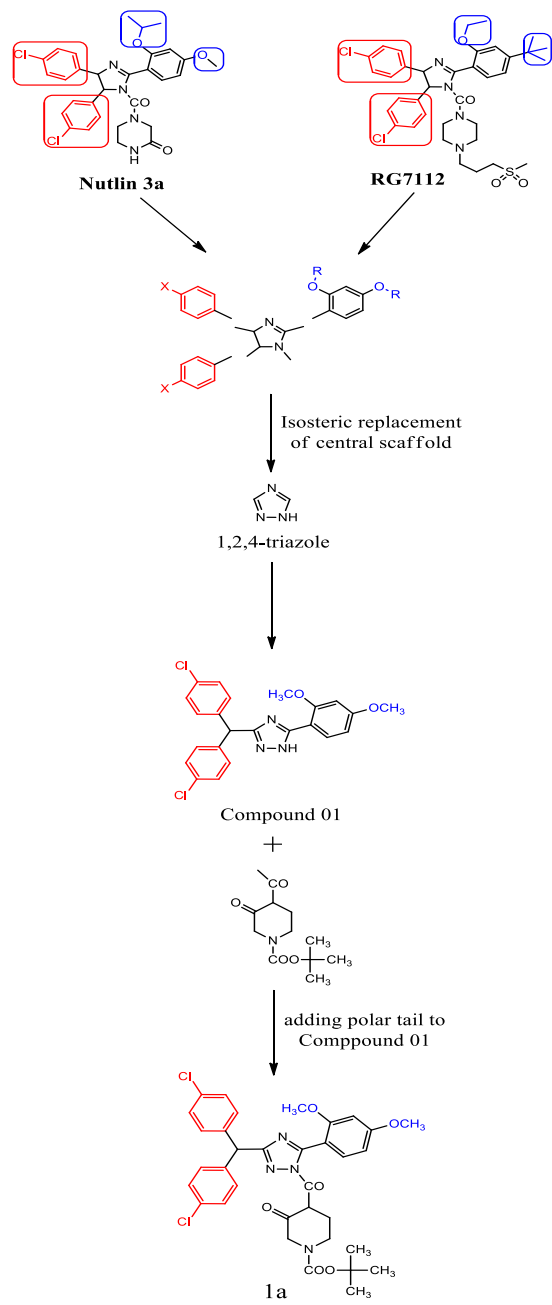

Figure 2. Drug design of compound 01 and lead 1a.

By studying the molecular descriptors of compound 01 (Table 1), it is found that all profiles of molecular descriptors of the compound 01 are in the range of average range of the reference compounds (Nutlins and RG7112), but the $\log P$ profile/value is very poor [26]. So compound 01 would have very low water solubility and cannot develop as a drug. To overcome this, we have added the polar tail into compound 01, so ultimately, it resulted in the lead compound 1a (figure 2). 
Evaluating the molecular descriptors of the lead 1a by using Lipinski filter (Sanjeevini) (table 2), it is clear that all the parameters of the molecular descriptors are in the range of average range. Same as of reference compound, lead 1a will have a good MDM2 inhibitory property and anti-cancer activity too.

Table 1. Molecular descriptors of compound 01.

\begin{tabular}{l|l|l|l|l|l} 
Compound & $\begin{array}{l}\text { Molecular weight } \\
(\mathbf{g} / \mathbf{m o l})\end{array}$ & $\begin{array}{l}\text { H-bond acceptor } \\
(\mathbf{n}+\mathbf{O})\end{array}$ & $\begin{array}{l}\text { H-bond } \\
\text { Donors } \\
(\mathbf{N H + O H})\end{array}$ & $\begin{array}{l}\text { LogP } \\
\text { Refractivity }\end{array}$ \\
\hline Compound 01 & 421 & 05 & 00 & -0.22 & 88.79
\end{tabular}

Table 2. Molecular descriptors of lead 1a and reference compounds.

\begin{tabular}{l|c|c|c|c|c} 
Compound & $\begin{array}{c}\text { Molecular weight } \\
\text { (g/mol) }\end{array}$ & $\begin{array}{c}\text { H-bond acceptor } \\
(\mathbf{n + O})\end{array}$ & $\begin{array}{c}\text { H-bond } \\
\text { donors } \\
\text { (NH+OH) }\end{array}$ & LogP & $\begin{array}{c}\text { Molar } \\
\text { Refractivity }\end{array}$ \\
\hline STD Range & 150 to 480 & 2 to 9 & 0 to 3 & -1 to 6 & 40 to 130 \\
\hline Nutlin 3a & 551 & 08 & 00 & -0.20 & 115.23 \\
\hline RG7112 & 679 & 08 & 00 & 1.07 & 151.88 \\
\hline Avg. Range & 615 & 08 & - & -0.34 to 0.63 & 133.55 \\
\hline 1a & 631 & 10 & 00 & -1.03 & 127.66
\end{tabular}

\subsection{Docking simulation.}

Nutlin 3a, RG7112, and lead 1a were submitted to PyRx software for the docking on the MDM2 protein. Autodock vina of PyRx docked the different possible orientation/conformation of the ligands on the active site of MDM2 protein [27]. Moreover, provide the score of 09 best orientations of the ligands. We had checked the different orientation/conformations, by using the Discovery Studio Visualizer (discussed in the receptorligand interactions portion). We visualize the binding of the lead 1a in the active site of the MDM2 protein by using the PyMOL Molecular Graphics System (figure 4). In our result, among the different orientation of the ligands, the Orientation with Zero is the best result. Furthermore, for the Binding Affinities: lower the value better than the docking.

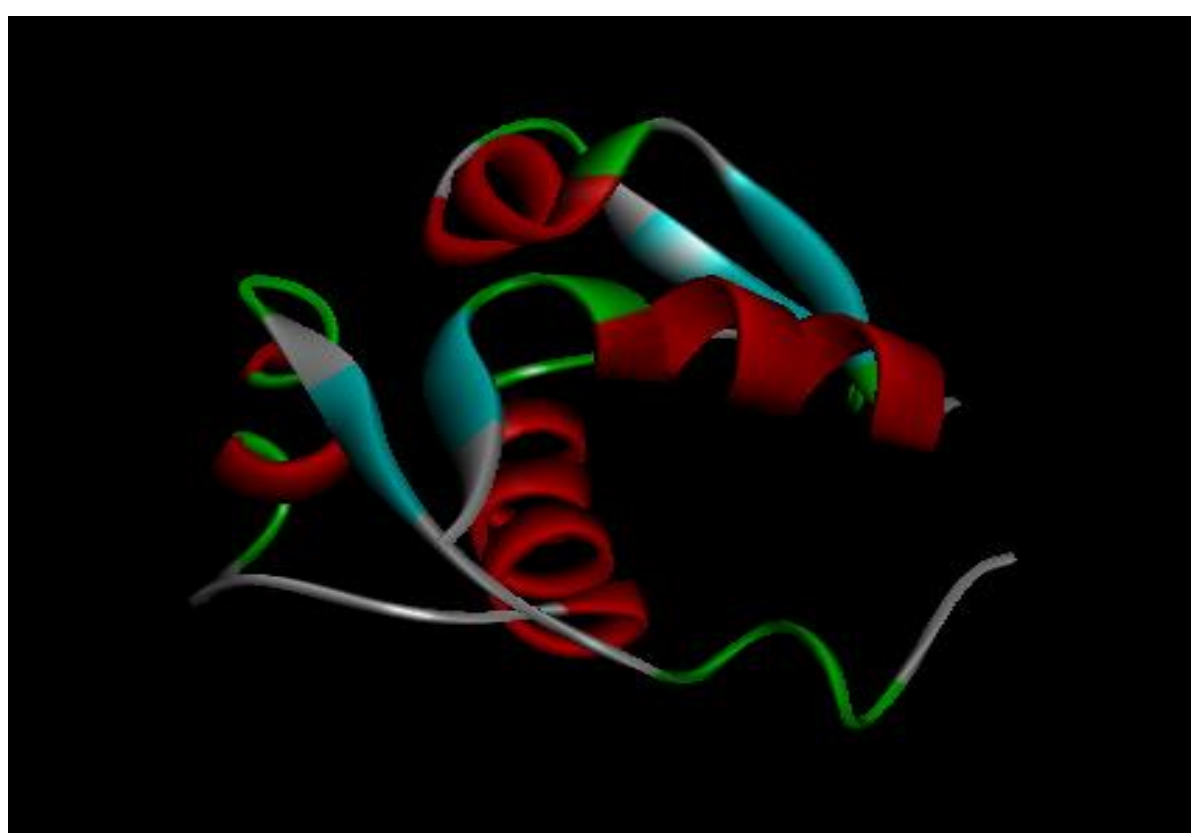

Figure 3. Structure of MDM2 protein after removing Hetatoms. 


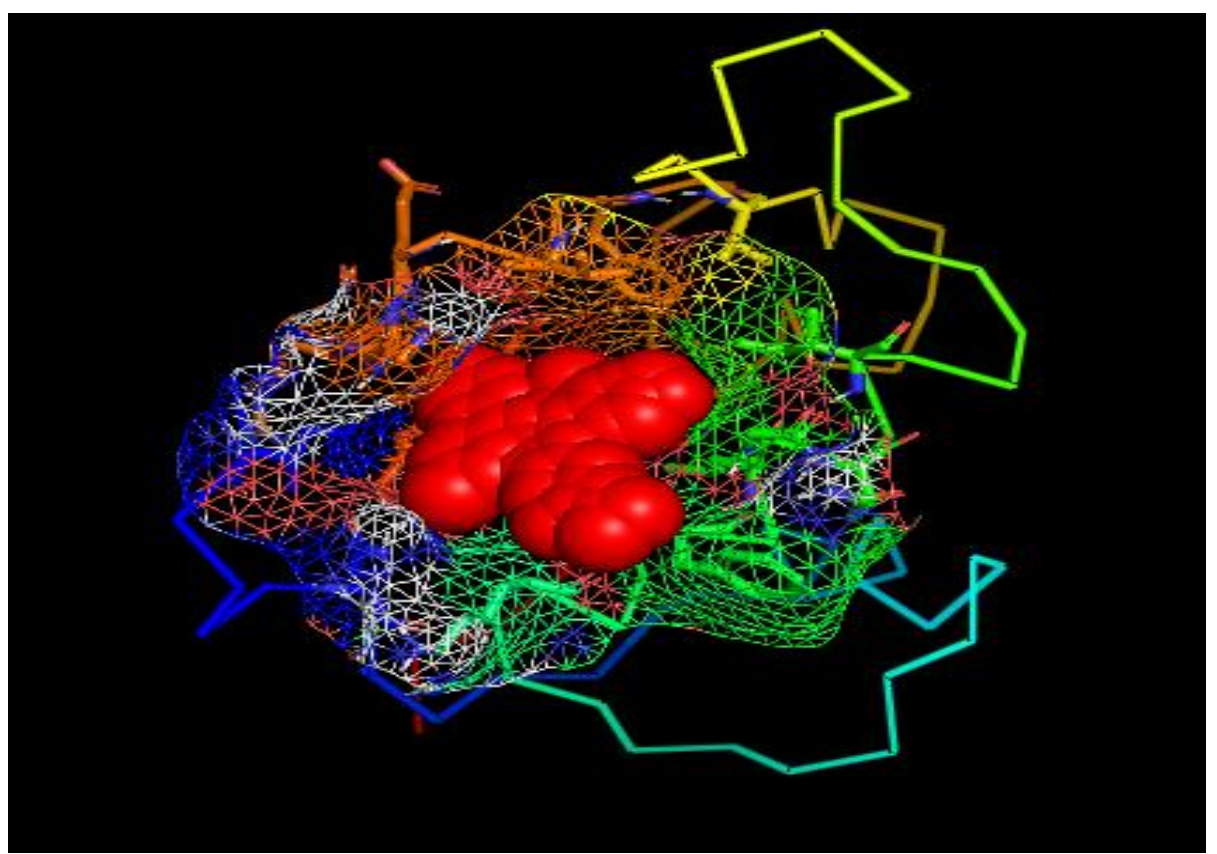

Figure 4. Binding of lead1a in the MDM2 pocket, (Mesh surface: Binding pocket of the MDM2 protein, Red Spheres: Lead 1a).

\subsection{Receptor-ligand interactions.}

Proper estimation of the ligand-receptor interaction is indispensable for the computerassisted drug design and discovery [28]. As of this, the interaction of the MDM2 inhibitors with the MDM2 protein is required to inhibit the MDM2 function. We reported the various kinds of interactions between the lead 1a and binding site residues of the MDM2 protein (figure 5). In this study, we mainly focused on the binding affinity, hydrogen bonding interaction, and hydrophobic interaction to quantify the ligand-receptor interactions [29].

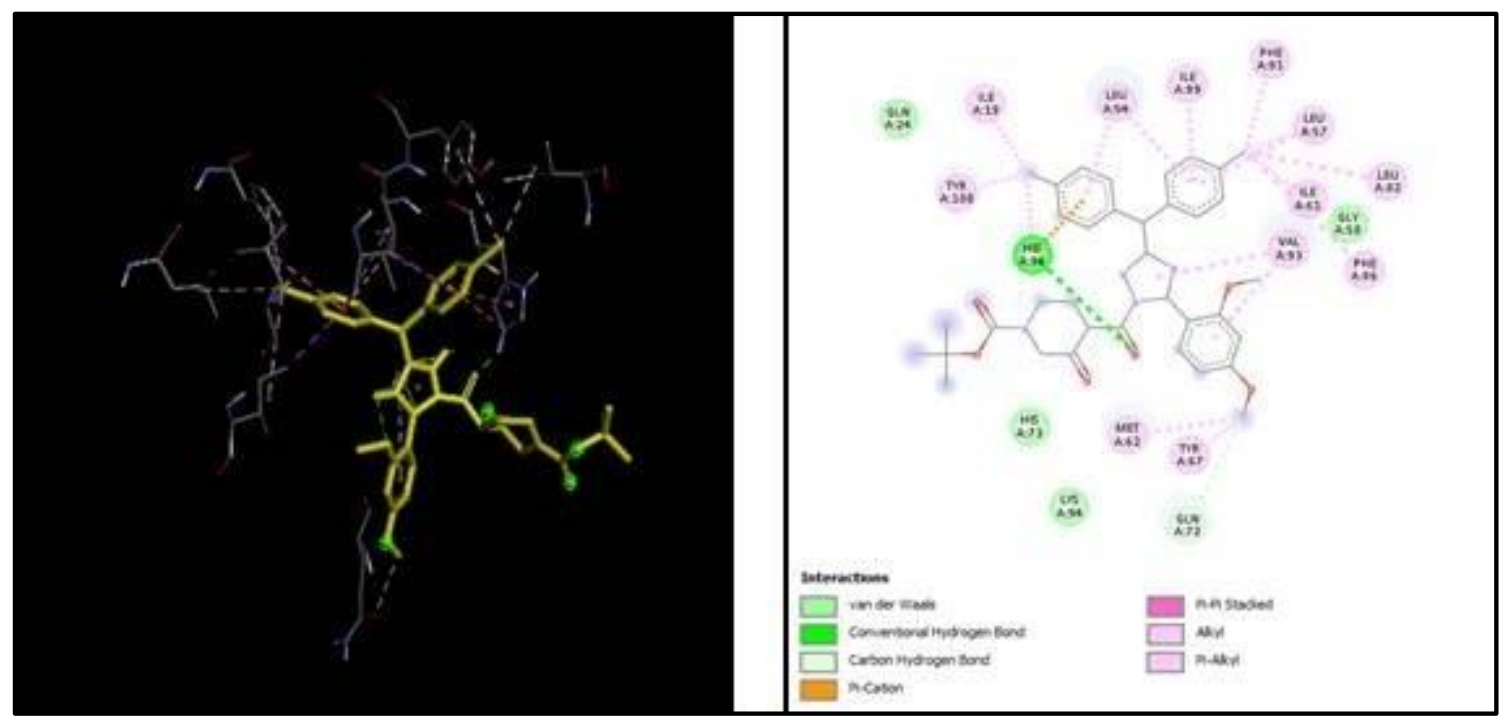

(a)

(b)

Figure 5. Various interactions of the lead 1a with active site residues (amino acids) of the MDM2 protein: (a) $3 \mathrm{D}$ representation of the various interactions; (b) 2D representation of the various interactions.

We have studied and evaluated the lead 1a binding pattern and its interaction with the ligand-binding site of MDM2 protein. We compare it with the p53 binding pattern. Lead 1a 
has bound in p53 binding pocket of MDM2 protein. Lead 1a shows the identical three-pocket bindings (Phe19, Trp23, Leu26) as of p53 protein.

The binding pattern of the lead 1a is similar to that of p53 protein. Lead 1a interact with all the amino acids of the MDM2's active site (except Val75, Ile101), as shown in table 3.

Table 3. Detail interactions of the lead 1a with amino acid residues (active site) of MDM2 protein.

\begin{tabular}{l|l|l|l}
$\begin{array}{l}\text { Interacting } \\
\text { moieties of lead 1a }\end{array}$ & Amino acid residues of the binding pocket & \\
\hline $\mathrm{Ar}-\mathrm{Cl}$ & $-\mathrm{Cl}$ & Ile19, Gln24, His96, Tyr100 & \\
\hline & Ar-ring & Leu54, His96 & \\
\hline $\mathrm{Ar}-\mathrm{Cl}$ & $-\mathrm{Cl}$ & Leu57, Gly58, Ile61, Leu82, Phen86, Phe91, & \\
\hline & Ar-ring & Leu54, Leu57, Ile99 & \\
\hline Triazole ring & & Va193 & \\
\hline $\mathrm{Ar}-\mathrm{OCH} 3$ & $-\mathrm{CH} 3$ & Met62, Tyr67 & \\
\hline & Ar-ring & Val93 &
\end{tabular}

His96 forms the three different bonds with the different moieties of lead 1a. One of its three bonds is bond with the Ar-ring of Ar-Cl (saffron bond in figure 5(b)). The bond length of Ar(ring)-His96 bond is 4.44 angstrom. Moreover, the type of bond is Pi-cation. Apart from the traditional interactions, lead 1a has shown the extra interaction with the Ile19, Gln24, Gly58, His73, Leu82, Lys94. From the traditional interaction with the amino acids of the MDM2's active site, interaction with the Val75 and Ile101 has been absent. Details of the bonds formed between lead 1a with active site residues (amino acids) of MDM2 protein has described in table 4 and figure 6.

Table 4. Bond lengths of lead 1a-MDM2 interactions.

\begin{tabular}{l|c|c} 
Ligand-receptor interaction & $\begin{array}{c}\text { Max. distance of interaction } \\
\text { (max. bond length) }\end{array}$ & $\begin{array}{c}\text { Min. distance of interaction } \\
\text { (min. bond length) }\end{array}$ \\
\hline lead 1a-MDM2 & 5.42 angstrom & 3.50 angstrom
\end{tabular}

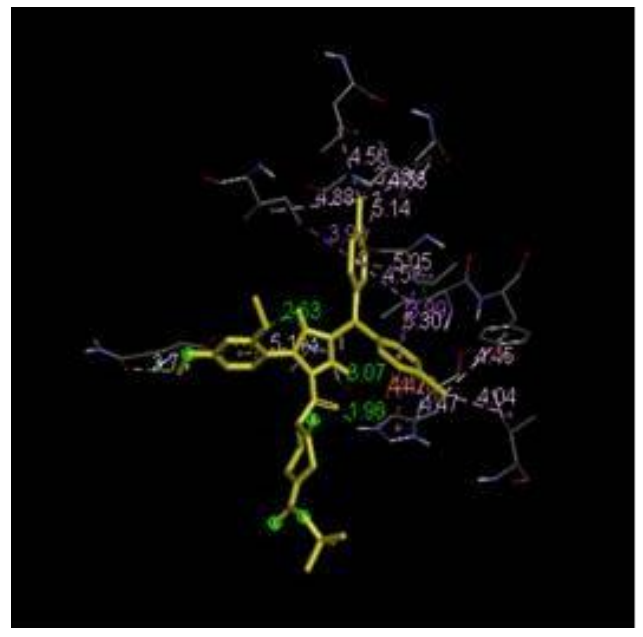

(a)

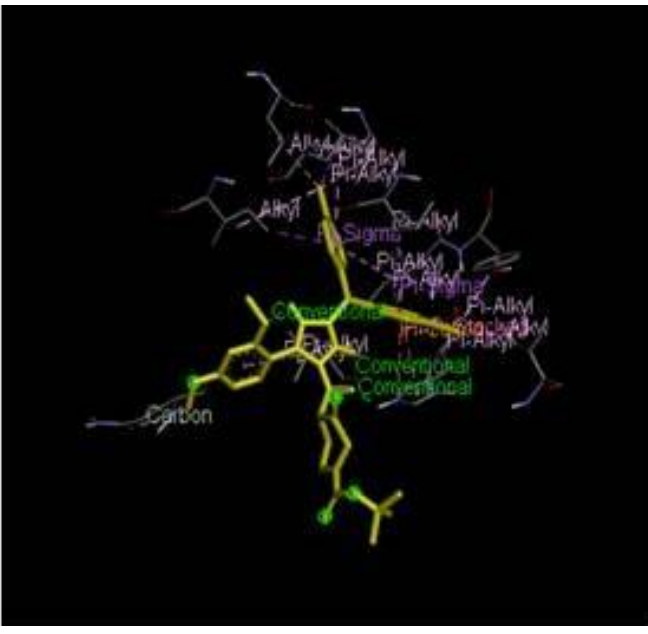

(b)

Figure 6. Distance and types of particular bonds formed by the interaction between lead 1a and active site residues (amino acids) of MDM2 protein: (a) distance of particular bonds; (b) types of particular bonds.

3.3.1. Binding affinity.

The biological response initiated by ligand depends upon the affinity of the binding. The high binding affinity is a product of the greater intermolecular force between the ligand 
and receptor protein and vice versa [30]. Therefore, the ligand-receptor interaction mainly depends upon the physico-chemical properties of the ligands [31, 32].

Post docking analysis revealed the binding affinities of the Nutlin 3a, RG7112, and lead 1a. By comparing the binding affinities of all the ligands (Table 5), It is observed the tight binding of lead 1a with MDM2 protein. LogP/molecular weight ratio of lead 1a has found to be good compare to RG7112. As the lead 1a has a good binding affinity, it will be having a strong biological response (MDM2 inhibition).

Table 5. Binding affinity and number of possible conformation of ligands.

\begin{tabular}{c|c|c|c} 
Sr No. & Compound & $\begin{array}{c}\text { No. of Conformations/ } \\
\text { Orientations }\end{array}$ & $\begin{array}{c}\text { Binding affinity } \\
\text { (kcal/mol) }\end{array}$ \\
\hline 01 & Nutlin 3a & 09 & -8.3 \\
\hline 02 & RG7112 & 09 & -7.4 \\
\hline 03 & 1a & 09 & -8.9
\end{tabular}

\subsubsection{Hydrogen bonding Interactions.}

H-bond potentiates the diverse biological drug response by facilitating the interaction of the ligand with the receptor protein [33, 34]. Hydrogen bonds strengthen the ligand-binding affinity by displacing protein-bound water into bulk solvent $[35,36]$.

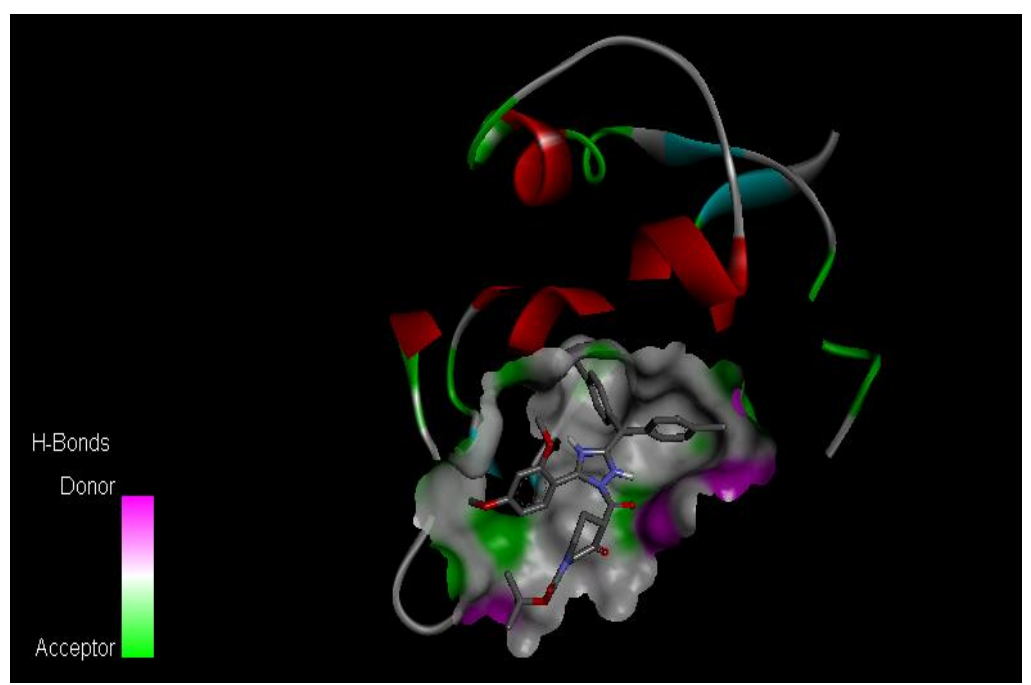

Figure 7. H-bonds interactions of the lead 1a with the active site of the MDM2 protein (cloud around the lead 1a shows the H-bond interaction region, green spot in the cloud: H-bond acceptor, a pink spot in the cloud: $\mathrm{H}-$ bond donors).

We assess the hydrogen bonding between lead 1a and MDM2 protein (figure 7). According to results, it is clear that H-bonds accelerate the lead 1a-MDM2 protein interaction. It revealed the bonding between lead 1a's H-bond acceptor and MDM2 protein's H-bond donors. During the hydrogen bonding, the water molecule's position and orientation are constrained by the protein. Moreover, H-bonds contribute to the polarity of the Lead 1a.

Table 6. H-bonds profile of the lead 1a.

\begin{tabular}{l|l|l|l} 
Compounds & Distance of H-bond & Types of H-bond & $\begin{array}{l}\text { Amino acid residue which } \\
\text { forms H-bond }\end{array}$ \\
\hline Lead 1a & 2.39 Angstrom & Conventional & His96
\end{tabular}

The details of the H-bond between lead 1a and active site residues of MDM2 protein has given in table 6. Plot showing the probability of H-bond forming residues of MDM2 protein was derived by using the DS Visualizer (figure 8). 


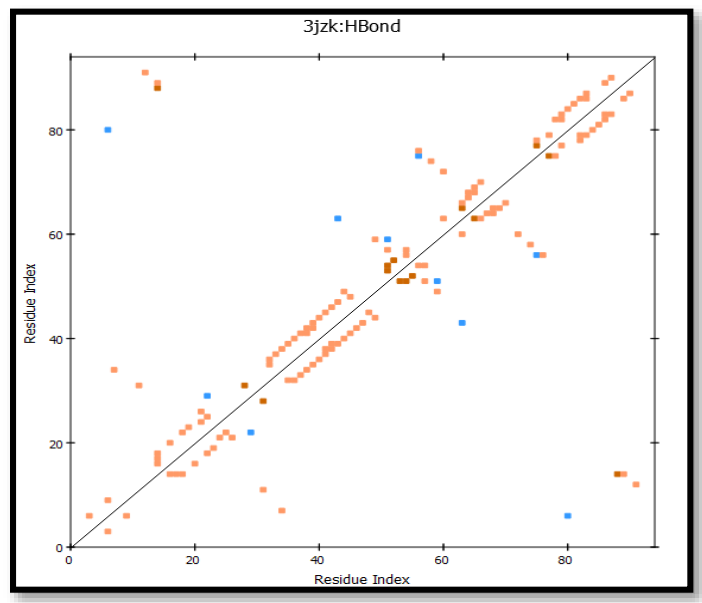

Figure 8. Plot of the probability of H-bond forming residues of MDM2 protein.

\subsubsection{Hydrophobic interaction.}

Hydrophobic interaction is an important player in ligand-receptor binding and activity. We visualized the hydrophobic interaction between the lead 1a and the MDM2 protein at the site of binding (figure 9,10). Since the lead 1a is non-polar, so this interaction is essential in the binding and elucidated drug response.

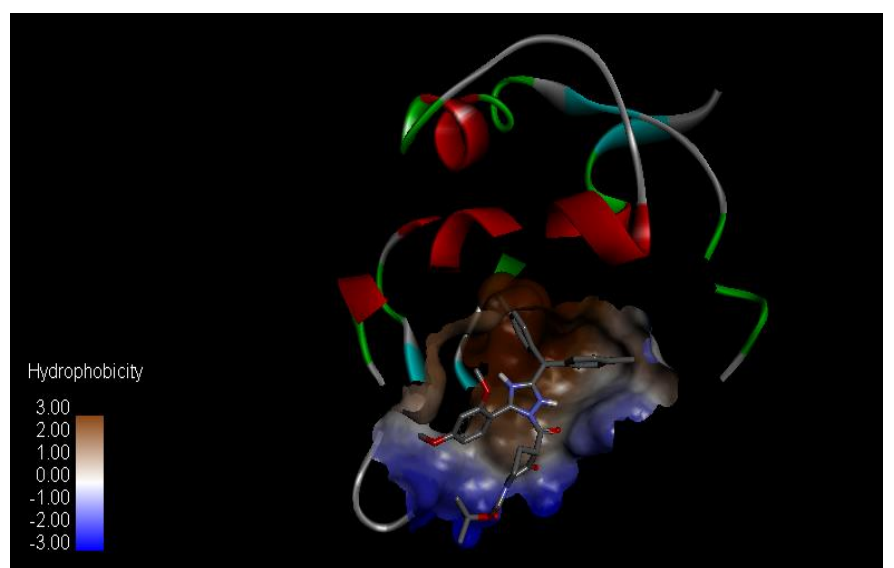

Figure 9. Hydrophobic interactions of the lead 1a with the active site of the MDM2 protein (cloud around the lead 1a shows the hydrophobic interaction region, a blue spot in the cloud: minimum distance of hydrophobic interactions, a brown spot in the cloud: maximum distance of hydrophobic interactions).

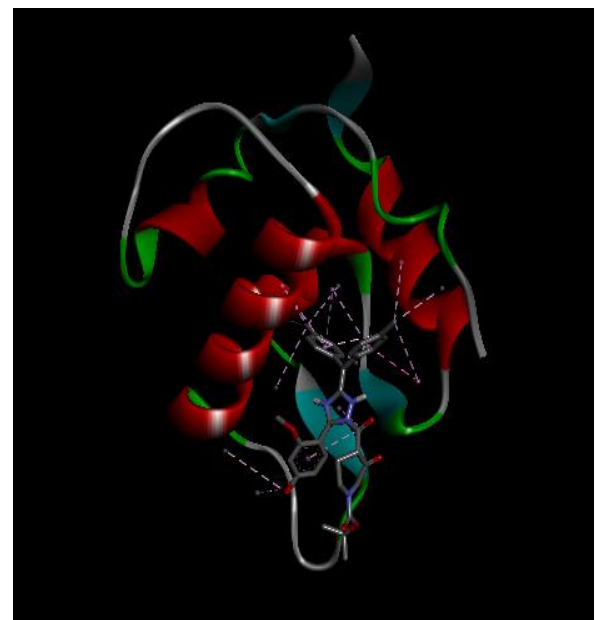

Figure 10. Formation of bonds by hydrophobic interactions between lead 1a and active site residues (amino acids) of MDM2 protein. 
We observe an inter-relationship between the hydrophobic interaction and H-bonds. Tight binding of lead 1a is observed if we optimized the hydrophobic interaction at the expense of H-bonds. Hydrogen bonding and hydrophobic interaction is a key player in stabilizing the lead 1a at the interface of the MDM2 protein. Plot showing the index of average hydrophobicity of the MDM2 residues was derived by the DS Visualizer (figure 11).

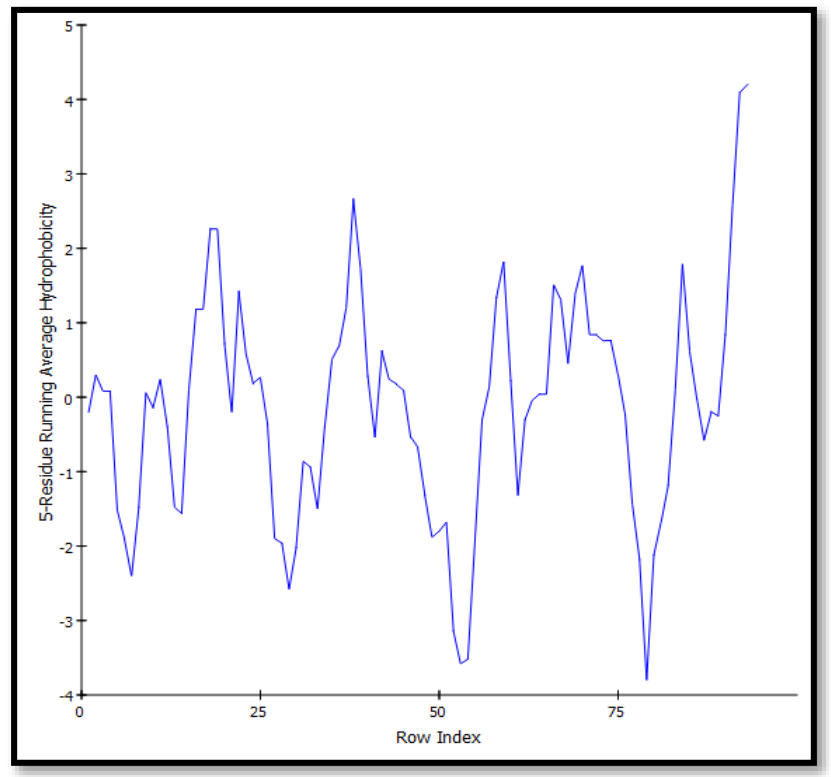

Figure 11. Plot of the index of average hydrophobicity of the MDM2 protein's residues.

\subsection{Discussions.}

In search of small-molecule p53-MDM2 interaction inhibitors, we designed the 1,2,4triazole based inhibitors using the Sanjeevini Drug Designing Software Suite. We design the first molecule, which is compound 01 . And further optimization of it leads to the potential lead molecule 1a.

In-silico study of a lead molecule (1a) and reference compounds (Nutlin 3a, RG7112) in MDM2 protein was performed. The designed lead 1a contains the 1,2,4-triazole as a central scaffold. The 1,2,4-triazole is an important heterocyclic moiety in medicinal chemistry. Moreover, it is having a wide range of biological activities [37]. 1,2,4-triazole can be synthesized by various methods [38, 39]. By adding the different substitution to the lead compound 1a, we can have different derivatives of the lead compound 1a.

Furthermore, by evaluating the ligand-target interaction, it has been cleared that we can alter the interaction and affinity by integrating the various functional group of ligand [40]. Results presented that $\mathrm{H}$-bonds and optimized hydrophobic interactions stabilize the ligands at the active site of MDM2 protein, and can help to alter binding affinity and drug efficacy.

The lead 1a showed a comparable result with potent MDM2 inhibitors (Nutlin 3a and RG7112). Lead 1a shows the three-pocket bindings by successfully mimicking the three important residues (Phe19, Trp23, and Leu26) of p53 in the binding pocket of the MDM2 protein [41].

The binding affinity of lead 1 a found as -8.9 , which is better than Nutlin $3 a(-15.6)$ and RG7112 (-7.4) (Table 5). Reference compound nutlin 3a was reported by the Vassilev and his colleagues at the Roche pharmaceuticals $[42,43]$. Nutlin $3 \mathrm{a}$ is the most potent compound of 
nutlin class. Nutlin 3a is having the IC50 value $90 \mathrm{nM}$. Alongside this, our lead 1a performed better than nutlin $3 \mathrm{a}$ so that it will be more potent than nutlin $3 \mathrm{a}$.

RG7112 was also designed and developed by Roche Pharmaceuticals. It was the first MDM2 inhibitor to enter into the clinical trials. IC50 value of RG7112 is $18 \mathrm{nM}$. RG7112 has a higher molecular weight than lead 1a (Table 2).

Polarity/mole, the weight ratio of lead 1a, is good than the RG7112. Because lead 1a have a more H-bonds acceptors than the RG7112 (table 2). Therefore lead 1a is having a better $\log$ P profile than the RG7112 (table 2). The $\log P$ value of the RG7112 is low so that it will have a low polarity and low bioavailability. Our lead 1a is more polar than the RG7112 so that it will have good bioavailability.

Nutlin 3a and RG7112 are both stereo-active compounds (figure 1). Hence, Nutlin 3a and RG7112 have multiple chiral centers, so their synthesis and purification is a very tedious and difficult process. Here our lead la does not contain any kind of chiral center, so its synthesis and purification can be done easily.

The data of the in-silico study shows that our design lead 1a has a good binding affinity along with good $\log \mathrm{P}$ (polarity). Therefore it will prove to be a potent inhibitor of the MDM2 protein. These data are indicating Lead 1a as a potential inhibitor of p53-MDM2 interaction.

\section{Conclusions}

Drug design is a pivotal task in the process of drug discovery. By studying the all-potent MDM2 inhibitors, which are under clinical trials, and structure-activity relationship studies can provide some leading principles for the design of the novel p53-MDM2 interaction inhibitors. The interaction between 553-MD2 proteins in the biological systems unveils the three-pocket binding and the p53 side-chain topology, which must be mimicked by drugs. To mimic the three points (Phe19, Trp23, Leu26) of the p53 topology is the key requirement for the successful development of the MDM2 inhibitor-based novel anti-cancer agents.

In this article, we discussed the design and in-silico study of the 1,2,4-triazole containing novel molecules, Compound 01, and Lead compound 1a. The design of the novel compound containing the 1,2,4-triazole as a central scaffold for the inhibition of the p53MDM2 interaction has arisen the hope for the result into the potent anti-cancer agents. During the in-silico study, the lead 1a was found to have three pockets binding into the MDM2 protein by perfectly mimicking the three residues of p53. With compared to Reference compounds (Nutlin 3a and RG7112), lead 1a showed a better result. Hence, the in-silico study indicated it as a successful MDM2 inhibitor and anti-cancer agent. However, there is a need to synthesis the design compound and to evaluate its in-vitro and in-vivo activity. Furthermore, we need to evaluate its actual IC50 value and bioavailability.

\section{Funding}

This research received no external funding.

\section{Acknowledgments}

The authors are thankful to the Department of Pharmaceutical Chemistry, Shree Dhanvantary Pharmacy College, Kim(E), Dist. : Surat 394 110, Gujarat, India., for providing support.

\section{Conflicts of Interest}


The authors declare no conflict of interest.

\section{References}

1. Nayak, S.K.; Khatik, G.; Narang, R.; Chopra, H.K. Design and Anti-cancer activity prediction of Dihyropyrimidinone based novel inhibitors of p53-MDM2 interaction. Asian. J. Pharm. Clin. Res. 2017, 110-116, https://doi.org/10.22159/ajpcr.2017.v10s4.21346

2. Makegowda, M.; Doddarevanna, R.H.; Mukundaswamy, C.K. Molecular docking and multitudinous spectroscopic studies to elucidating proton-pump inhibitor a lansoprazole binding interaction with bovine serum albumin. Biointerface Res Appl Chem 2019, 9, 4015-4021, https://doi.org/10.33263/BRIAC94.015021.

3. Husain, Q. Nanosupport bound lipases their stability and applications. Biointerface Res Appl Chem 2017, 7, 2194-2216.

4. $\quad$ Ding, K.; Lu, Y.; Nikolovska-Coleska, Z.; Qiu, S.; Ding, Y.; Gao, W.; Stuckey, J.; Krajewski, K.; Roller, P.P.; Tomita, Y.; Parrish, D.A.; Deschamps, J.R.; Wang, S. Structure-Based Design of Potent Non-Peptide MDM2 Inhibitors. Journal of the American Chemical Society 2005, 127, 10130-10131, https://doi.org/10.1021/ja051147z.

5. Newman, D.J.; Cragg, G.M. Natural Products as Sources of New Drugs over the Last 25 Years. J. Nat. Prod. 2007, 70, 461-477, https://doi.org/10.1021/np068054v.

6. $\quad$ Agrafiotis, D.K.; Bandyopadhyay, D.; Wegner, J.K.; Vlijmen, H.K. Recent Advances in Chemoinformatics J. Chem. Inf. Model. 2007, 47, 1279-1293, https://doi.org/10.1021/ci700059g.

7. Valerio Jr, L.G.; Choudhurib, S. Chemoinformatics and chemical genomics: potential utility of in silico methods. J. Appl. Toxicol. 2012, https://doi.org/10.1002/jat.2804.

8. Hopkins, A.L.; Keseru, G.M.; Leeson, P.D.; Rees, D.C.; Reynolds, C.H. The role of ligand efficiency metrics in drug discovery. Nat. Rev. Drug Discov. 2014, 13, 105-121, https://doi.org/10.1038/nrd4163.

9. Hong, H.; Xie, Q.; Ge, W.; Qian, F.; Fang, H.; Shi, L.; Su, Z.; Perkins, R.; Tong, W. Mold2, Molecular Descriptors from 2D Structures for Chemoinformatics and Toxicoinformatics. Journal of Chemical Information and Modeling 2008, 48, 1337-1344, https://doi.org/10.1021/ci800038f.

10. Hari, S. In silico molecular docking and ADME/T analysis of plant compounds against IL17A and IL18 targets in gouty arthritis. J. Appl. Pharm. Sci. 2019, 9, 018-026, https://doi.org/10.7324/JAPS.2019.90703.

11. Paul, N.; Kellenberger, E.; Bret, G.; Muller, P.; Rognan, D. Recovering the True Targets of Specific Ligands by Virtual Screening of the Protein Data Bank. Proteins 2004, 54, 671-680, https://doi.org/10.1002/prot.10625.

12. Kitchen, D.B.; Decornez, H.; Furr, J.R.; Bajorath, J. Docking and Scoring in Virtual screening for Drug discovery: Methods and applications. Nat. Rev. Drug. Discov. 2004, 3, 935-949, https://doi.org/10.1038/nrd1549.

13. Thiel, K.A. Structure-aided drug design's next generation. Nat. Biotechnol. 2004, 22, 513-519, https://doi.org/10.1038/nbt0504-513.

14. Pratama, M.R.F.; Gusdinar, T. Docking study of secondary metabolites from Glycyrrhiza glabra as PPAR- $\gamma$ agonist. Biointerface Res Appl Chem 2019, 9, 4006-4010, https://doi.org/10.33263/BRIAC94.006010.

15. Punvichai, T.; Pioch, D. Co-valorization of agro-industry by-products: effect of citrus oil on the quality of soap derived from palm fatty acid distillate and spent bleaching clay. Lett Appl NanoBioScience 2019, 8, 571-575, https://doi.org/10.33263/LIANBS83.571575.

16. Böttger, A.; Böttger, V.; Garcia-Echeverria, C.; Chène, P.; Hochkeppel, H.-K.; Sampson, W.; Ang, K.; Howard, S.F.; Picksley, S.M.; Lane, D.P. Molecular characterization of the hdm2-p53 interaction11Edited by J. Karn. Journal of Molecular Biology 1997, 269, 744-756, https://doi.org/10.1006/jmbi.1997.1078.

17. Uhrinova, S.; Uhrin, D.; Powers, H.; Watt, K.; Zheleva, D.; Fischer, P.; McInnes, C.; Barlow, P.N. Structure of Free MDM2 N-terminal Domain Reveals Conformational Adjustments that Accompany p53-binding. Journal of Molecular Biology 2005, 350, 587-598, https://doi.org/10.1016/j.jmb.2005.05.010.

18. Toledo, F.; Wahl, G.M. MDM2 and MDM4: p53 regulators as targets in anti-cancer therapy. Int. J. Biochem. Cell. B. 2007, 39, 1476-1482, https://dx.doi.org/10.1016\%2Fj.biocel.2007.03.022.

19. Khatab, T.K.; Abdelghany, A.M.; Kandil, E.M.; Elsefy, D.E.; El-Mekabaty, A. Hydroxyapatite/ZnCl2 nanoflakes: an efficient catalyst for the synthesis of 2-arylbenzothiazoles with molecular docking and anti-oxidant evaluation. Biointerface Res Appl Chem 2020, 10, 5182-5187, https://doi.org/10.33263/BRIAC102.182187.

20. Elshemy, N.S.; Nassar, S.H.; El-Taieb, N.M.; Shakour, A.A.A.; Elmekawy, A.M.; Hassabo, A.G. Effect of different fabrics types on the adsorption of air pollution in residential and industrial atmosphere in CairoEgypt. Lett Appl NanoBioScience 2019, 8, 682-691, https://doi.org/10.33263/LIANBS84.682691.

21. Ortiz, N.E.; Neochoritis, C.G.; Domling, A. How to Design a Successful p53-MDM2/X Interaction Inhibitor: A Thorough Overview Based on Crystal Structures. ChemMedChem. 2016, 11, 757-772, https://doi.org/10.1002/cmdc.201500487.

22. Vassilev, L.T.; Vu, B.T.; Graves, B.; Carvajal, D.; Podlaski, F.; Filipovic, Z.; Kong, N.; Kammlott, U.; Lukacs, C.; Klein, C.; Fotouhi, N.; Liu, E.A. In Vivo Activation of the p53 Pathway by Small-Molecule Antagonists of MDM2. Science 2004, 303, 844-848, https://doi.org/10.1126/science.1092472. 
23. Jacob, L.; Vert, J.P. Protein-ligand interaction prediction: an improved chemogenomics approach. Bioinformatics 2008, 24, 2149-2156, https://doi.org/10.1093/bioinformatics/btn409.

24. Vaishali, S.; Deepika, R.; Anuj, K.; Himanshu, C. Formulation and evaluation of herbal tablet containing Terminalia chebula extract. Lett Appl NanoBioScience 2019, 8, 692-697, https://doi.org/10.33263/LIANBS84.692697.

25. Skrypnyk, M.; Petrushanko, T.; Neporada, K.; Bubnov, R.; Shcherbakov, O.; Spivak, M. Effectiveness of nanocrystalline cerium dioxide for secondary prevention of inflammatory periodontal diseases in young individuals with obesity. Lett Appl NanoBioScience 2019, 8, 754-761, https://doi.org/10.33263/LIANBS84.754761.

26. Chaudhary, S.; Majhi, S.; Verma, M. Biomarkers for epilepsy - a new ray of hope. Lett Appl NanoBioScience 2020, 9, 830-839, https://doi.org/10.33263/LIANBS91.830839.

27. Otuechere, C.A.; Durugbo, E.U.; Adesanya, O.; Omotolani, F.O.; Osho, A. Essential oil of Alchornea laxiflora (benth): phytochemical, antimicrobial and toxicity evaluations. Lett Appl NanoBioScience 2019, 8, 661-665, https://doi.org/10.33263/LIANBS83.661665.

28. Paul, S.; Kulal, R.; Nath, R. Comparative evaluation of expression of VEGF (vascular endothelial growth factors) in periodontal tissues of healthy, chronic and aggressive periodontitis patients: an immunohistochemical study. Lett Appl NanoBioScience 2020, 9, 784-788, https://doi.org/10.33263/LIANBS91.784788.

29. Hornak, V.; Dvorsky, R.; Sturdik, E. Receptor-Ligand Interaction and Molecular Modelling. Gen. Physiol. Biophys. 1999, 18, 231-248.

30. Marsh, L. Prediction of Ligand Binding Using an Approach Designed to Accommodate Diversity in ProteinLigand Interactions. PLoS One 2011, 6, 1-10, https://doi.org/10.1371/journal.pone.0023215.

31. Wang, C.; Liu, J.; Luo, F.; Deng, Z.; Hu, Q.N. Predicting target-ligand interactions using protein ligandbinding site and ligand substructures. BMC Syst. Biol. 2015, 9, 1-10, https://doi.org/10.1186/1752-0509-9S1-S2.

32. Ullah, N.; Ullah, A.; Rasheed, S. Green synthesis of copper nanoparticles using extract of Dicliptera Roxburghiana, their characterization and photocatalytic activity against methylene blue degradation. Lett Appl NanoBioScience 2020, 9, 897-901, https://doi.org/10.33263/LIANBS91.897901.

33. Salentin, S.; Haupt, V.J.; Daminelli, S.; Schroeder, M. Polypharmacology rescored: Protein-ligand interaction profiles for remote binding site similarity assessment. Prog. Biophys. Mol. Biol. 2014, 116, 174186, https://doi.org/10.1016/j.pbiomolbio.2014.05.006.

34. Sawada, T.; Fedorov, D.G.; Kitaura, K. Role of the key mutation in the selective binding of avian and human influenza hemagglutinin to sialosides revealed by quantum-mechanical calculations. J. Am. Chem. Soc. 2010, 132, 16862-16872, https://doi.org/10.1021/ja105051e.

35. Ross, G.A.; Morris, G.M.; Biggin, P.C. Rapid and accurate prediction and scoring of water molecules in protein binding sites. PLoS One 2012, 7, https://doi.org/10.1371/journal.pone.0032036.

36. Barillari, C.; Taylor, J.; Viner, R.; Essex, J.W. Classification of water molecules in protein binding sites. $J$. Am. Chem. Soc. 2007, 129, 2577-2587, https://doi.org/10.1021/ja066980q.

37. Lauro, F.V.; Marcela, R.N.; Virginia, M.A.; Socorro, H.M.; Maria, L.R.; Elodia, G.C.; Eduardo, P.G.; Rolando, G.M.; Perla, P.G.; Regina, C.C.; Saidy, E.H. Design and synthesis of pyranacyclodecaphen-3,6diyliden)bis(azanylidene))bis(ethan-1-amine) derivative with positive inotropic activity. Biointerface Res Appl Chem 2018, 8, 3161-3169.

38. Shirish, A. Synthesis and Catalytic Applications of 1,2,4- Triazoles in Oxidative Processes. PhD Thesis, University of Tennessee: USA, 2012, https://trace.tennessee.edu/cgi/viewcontent.cgi?article=2661\&context=utk_graddiss.

39. Yeung, K.S.; Farkas, M.E.; Kadow, J.F.; Meanwell, N.A. A base-catalyzed, direct synthesis of 3,5disubstituted 1,2,4-triazoles from nitriles and hydrazides. Tetrahedron Lett. 2005, 46, 3429-3432, http://dx.doi.org/10.1016\%2Fj.tetlet.2005.02.167.

40. Wang, J.C.; Lin, J.H. Scoring Functions for Prediction of Protein-Ligand Interactions. Curr. Pharm. Des. 2013, 19, 1-9, https://doi.org/10.2174/1381612811319120005.

41. Liu, S.X.; Geng, Y.Z.; Yan S.W. Structural effects and competition mechanisms targeting the interactions between p53 and MDM2 for cancer therapy. Front. Phys. 2017, 12, 1-12, https://doi.org/10.1007/s11467017-0667-9.

42. Efeyan, A.; Molina, A.O; Miguel, S.V.; Herranz, D.; Vassilev, L.T.; Serrano, M. Induction of p53Dependent Senescence by the MDM2 Antagonist Nutlin-3a in Mouse Cells of Fibroblast Origin. Cancer Res. 2007, 67, 7350-7357, https://doi.org/10.1158/0008-5472.can-07-0200.

43. Vu, B.; Wovkulich, P.; Pizzolato, G.; Lovey, A.; Ding, Q.; Jiang, N.; Liu, J.J.; Zhao, C.; Glenn, K.; Wen, Y.; Tovar, C.; Packman, K.; Vassilev, L.; Graves, B. Discovery of RG7112: A Small-Molecule MDM2 Inhibitor in Clinical Development. ACS Med. Chem. Lett. 2013, 4, https://doi.org/10.1021/ml4000657. 